\section{Negative Muons and the Isotopic Composition of the Rare Gases in the Earth's Atmosphere}

WE wish to draw attention to the possible influence negative muons may have had on the isotopic composition of the rare gases now present in the Earth's atmosphere and crust and in meteorites. The specific reaction to be considered is of the form

negative muon + target nuclide $(A, Z) \rightarrow$ rare gas nuclide $(A, Z-1) \rightarrow$ rare gas nuclide $(A-x, Z-1)+x$ neutrons +

neutrino

where $x$ is the neutron multiplicity of the target nuclide. A detailed discussion of this muon capture reaction was first given by Fermi and Teller ${ }^{1}$. Suggestions that it might be possible to observe the reaction products resulting from the bombardment of the Earth's erust by cosmic-ray produced neutrons and negative muons have been made by several authors ${ }^{2-5}$.

The present muon flux of $10^{-2} \mathrm{~cm}^{-2} \mathrm{~s}^{-1}$, if maintained over $4.5 \times 10^{9}$ years, is insufficient by a factor of $\sim 10^{6}$ to produce the isotopic differences observed between the rare gases in the terrestrial atmosphere and those found in primitive meteorites. There is no evidence to indicate that the muon flux was higher in the past; indeed, data from stable and radioactive cosmogenic nuclides suggest that the cosmic radiation has been constant over at least the past $2 \times 10^{9}$ years (ref. 6 ).

It is conceivable, however, that a higher muon flux prevailed at a still earlier stage in the primitive solar nebula. Bernas et al.7 have proposed that $\mathrm{Lj}, \mathrm{Be}$ and $\mathrm{B}$ were synthesized in the solar nebula by charged particle irradiation. They suggest that high energy protons impinged on a low density solar nebula, thus producing the $\mathrm{Li}, \mathrm{Be}$ and $\mathrm{B}$. These conditions seem to be satisfactory for both initiating and propagating a high muon flux.

It is not our intention, however, to suggest how this required muon flux was produced but rather to point out how its presence could have influenced the isotopic abundances of the rare gases.

Negative muons, reacting with alkali element target nuclides, will produce rare gases the isotopic abundance patterns of which will depend critically on the neutron multiplicities of the individual isotopes of each target element. Significantly, some of the isotopes produced in greatest yield are the very ones which seem necessary in order to explain the observed isotopic differences between the noble gases found in the terrestrial atmosphere and in meteorites.

Table 1. TARGET ELENENTS AND PRODUCTS AFTER MUON BOMBARDMENT Major target Rare gas element

\begin{tabular}{ccl}
$\begin{array}{c}\text { Clement } \\
\mathrm{Li}\end{array}$ & produced & \multicolumn{2}{c}{ Comment } \\
$\mathrm{Na}$ & $\mathrm{He}$ & Low yield of ${ }^{4} \mathrm{He}$ \\
$\mathrm{K}$ & $\mathrm{Ne}$ & High yield of ${ }^{22} \mathrm{Ne}$ \\
$\mathrm{Rb}$ & $\mathrm{Hr}$ & High yield of ${ }^{38 \mathrm{Ar}}$ \\
$\mathrm{Cs}$ & $\mathrm{Kr}$ & ${ }^{86} \mathrm{Kr}$ dominates the yield pattern \\
& $\mathrm{Xe}$ & Does not produce ${ }^{134} \mathrm{Xe}$ or ${ }^{136} \mathrm{Xe}$. Maxi- \\
& & mum yicld at ${ }^{132} \mathrm{Xe}$. Possible small \\
& & contribution at ${ }^{130} \mathrm{Xe}$
\end{tabular}

Table I indicates those target and product nuclides which have a special significance in relation to rare gas studies.

Target nuclides, other than those listed, may also have contributed to the production pattern by means of a twostage process involving negative muon capture followed by positron decay or electron capture.

The general isotopic pattern to be expected for some of the target elements listed has been described by Hagan ${ }^{5}$. We cannot discuss the many implications of this muon flux hypothesis in relation to all the rare gases in this communication and so neon is considered as a specific example.

Atmospheric neon, with ${ }^{20} \mathrm{Ne} /{ }^{2} \mathrm{Ne}=9 \cdot 8$, is generally regarded as a mixture of solar neon $\left({ }^{20} \mathrm{Ne} /{ }^{22} \mathrm{Ne}_{\theta}=12.5\right)$ and planetary noon $\left({ }^{20} \mathrm{Ne} /{ }^{22} \mathrm{Ne} \sim 8.2\right.$ ) (see ref. 8). In the present picture, it seems possible that up to 30 per cent of the ${ }^{22} \mathrm{Ne}$ in the Earth's atmosphere has resulted from the capture of negative muons by ${ }^{23} \mathrm{Na}$.

An important number in this respect would be the experimentally observed value for the ${ }^{21} \mathrm{Ne} /{ }^{22} \mathrm{Ne}$ ratio resulting from the bombardment of ${ }^{23} \mathrm{Na}$ by negative muons. Unfortunately, this ratio has not been measured. Hagan ${ }^{5}$ gives an estimate for this figure of $0 \cdot 2 \pm 0 \cdot 14$, but he has been forced to extrapolate from the published data of MacDonald et al. ${ }^{9}$, which add an additional error to his estimate. Atmospheric Ne would now be considered a mixture of solar type $\mathrm{Ne}$ with muon produced $\mathrm{Ne}$ in suitable proportions.

Although the other rare gases each present special problems, the muon contribution to their isotopic composition would still be significant in some cases.

A critical determining factor in producing an anomaly is the quantity of a target nuclide that was available for the muon capture process. Because the atom ratio of $\mathrm{Na}$ to $\mathrm{Cs}$ in the Earth's crust is moderately large, the addition of some 30 per cent to the ${ }^{22} \mathrm{Ne}$ atmospheric abundance implies only $l$ per cent or so addition to the ${ }^{132} \mathrm{Xe}$ abundance. If the elemental abundance values for a chondritic Earth model are substituted rather than crustal values, the muon produced ${ }^{132} \mathrm{Xe}$ contribution for the same ${ }^{22} \mathrm{Ne}$ production will be smaller. Similar estimates may be made for $\mathrm{K}$ and $\mathrm{Rb}$ as long as the altered abundances of their radioactive nuclides are taken into account.

In spite of the many obvious difficulties associated with this model, it seems most significant that for a single value of time integrated negative muon flux, the muon capture reaction can simultaneously account for several of the isotopic anomalies observed in the atmospheric rare gases.

In particular it provides the following rare gas components from alkali element targets. (a) Neon with a low ${ }^{21} \mathrm{Ne} /{ }^{22} \mathrm{Ne}$ ratio. (b) $\mathrm{Kr}$ with an ${ }^{86} \mathrm{Kr} /{ }^{84} \mathrm{Kr}$ ratio that is much higher than that of atmospheric Kr. (c) Xenon with an isotopic pattern that is a maximum at ${ }^{132} \mathrm{Xe}$ and decreases with mass. Whether the yield at ${ }^{130} \mathrm{Xe}$ relative to ${ }^{132} \mathrm{Xe}$ is significant can only be surmised. The muon capture reaction does not produce ${ }^{134} \mathrm{Xe}$ or ${ }^{138} \mathrm{Xe}$ so that these isotopes are absent from muon produced xenon.

Rare gas components with isotopic patterns very similar to these seem to be required if the atmospheric rare gases are to be derived from the primitive gases found in certain meteorites.

The low energy neutron flux produced in situ by the muon capture reaction may also have been significant in the case of nuclides with very low abundances.

We thank Drs R. Ganapathy, J. W. Larimer, G. W. Reed, A. Turkevich and Professor E. Anders for discussion and critical comment. This work was supported by the Research Grants Committee of the University of Western Australia and an AEC contract.

\section{P. M. JEFFERY*}

Enrico Fermi Institute,

University of Chicago.

Department of Nuclear Physics.

\section{P. J. HAGAN}

University of Oxford.

Received May 12, 1969.

* On Ieave from Physics Department, University of Western Australia.

${ }^{1}$ Fermi, E., and Teller, E., Phys, Rev., 72, 399 (1947).

2 Davis, R., and Schaeffer, O. A., Ann. NY Acad. Sci., 62, 105 (1955).

${ }^{3}$ Rama, and Honda, M., J. Geophys. Res., 66, 3533 (1961).

${ }^{4}$ Rama, Bull. Nat. Geophys. Res. Inst., 1, 241 (1963).

5 Hagan, P. J., thesis, University of Western Australia (1968).

${ }^{B}$ Geiss, J., Oeschger, H., and Schwarz, U., Space Sci. Rev., 1, 197 (1962).

'Bernas, R., Gradsztajn, L., Reeves, H., and Schatzman, E., Ann. Phys., 44 426 (1967).

${ }^{8}$ Pepin, R. O., Eanth Planet. Sci. Leti., 2, 13 (1967). MacDonald, B., Diaz, J. A., Kaplan, S. N., and Pyle, R. V., Phys, Rev., 139
B1253 (1965). 